British Journal of Nutrition (2022), 128, 1082-1089

doi:10.1017/S0007114521004207

(C) The Author(s), 2021. Published by Cambridge University Press on behalf of The Nutrition Society. This is an Open Access article, distributed under the terms of the Creative Commons Attribution licence (https://creativecommons.org/licenses/by/4.0/), which permits unrestricted reuse, distribution, and reproduction in any medium, provided the original work is properly cited.

\title{
Association of dietary inflammatory index and metabolic syndrome in the elderly over 55 years in Northern China
}

\author{
Ruiqiang $\mathrm{Li}^{1} \dagger$, Wenqiang Zhan ${ }^{2} \ddagger$, Xin Huang ${ }^{1}$, Zechen Zhang ${ }^{1}$, Meiqi Zhou ${ }^{1}$, Wei Bao ${ }^{1}$, Qingxia Li $^{1}$ and \\ Yuxia $\mathrm{Ma}^{1}{ }^{\text {*i }}$ \\ ${ }^{1}$ Department of Nutrition and Food Hygiene, School of Public Health, Hebei Medical University, Hebei Province Key Laboratory \\ of Environment and Human Health, Shijiazhuang, People's Republic of China \\ ${ }^{2}$ School of Public Health, Shanghai Jiao Tong University School of Medicine, Shanghai 200025, People's Republic of China \\ (Submitted 28 June 2021 - Final revision received 15 September 2021 - Accepted 4 October 2021 - First published online 18 October 2021)
}

\section{Abstract}

We assessed the association between the dietary inflammatory index (DII) and the development of metabolic syndrome in the elderly over 55 years in Northern China. The data of 1936 Chinese adults aged 55 years and over from a community-based neurological disease cohort study from 2018 to 2019 were analysed. Multiple logistic regression and restricted cubic splines regression were used for analysis, and social demographics, lifestyle and health-related factors were adjusted. In the fully adjusted model, the risk of metabolic syndrome increased by $1 \cdot 28$-fold in people with a pro-inflammatory diet. When we divide the metabolic syndrome by its components, high pro-inflammatory diet and hyperglycaemia, TAG, hypertension and abdominal obesity, we failed to observe a significant association between a high pro-inflammatory diet and HDL-cholesterol. However, these associations are moving in the expected direction. At the same time, the results of BMI subgroup analysis showed that with the increase of DII, obese people are at increased risk of metabolic syndrome, hyperglycaemia, high TAG, hypertension and abdominal obesity. Also in overweight people, the increase in DII is accompanied by an increased risk of hyperglycaemia and abdominal obesity. Higher inflammatory diet is related to metabolic syndrome, hypertension, hyperglycaemia, abdominal obesity and hypertriglyceridaemia. Further research is needed to confirm the role of inflammation and diet in the development of metabolic syndrome; however, it is desirable to reduce the dietary components associated with inflammation.

Key words: Dietary inflammatory index: Elderly: Metabolic syndrome: Nutrition: Diet

Metabolic syndrome is a common metabolic disorder and has become a public health challenge worldwide ${ }^{(1)}$. It is the simultaneous occurrence of obesity, insulin resistance, atherosclerotic dyslipidaemia (high TAG, LDL-cholesterol) and high blood pressure. It is estimated that $20-30 \%$ of adults suffer from the metabolic syndrome in the world. Metabolic syndrome is associated with an increased risk of type 2 diabetes, non-alcoholic fatty liver, myocardial infarction and stroke. Therefore, it is the main cause of morbidity and mortality worldwide ${ }^{(2)}$.

Metabolic syndrome has become one of the most common chronic diseases in the elderly ${ }^{(3)}$. Some studies have shown that metabolic syndrome and its components are important factors in the progression of atherosclerotic disease in the elderly ${ }^{(4)}$. A metabolic syndrome is a group of metabolic disorders with unknown molecular mechanisms. More and more studies have found that the onset and progression of metabolic syndrome are closely related to inflammation ${ }^{(5)}$. What is more, recent evidence suggests that metabolic syndrome is a consequence of low-grade inflammation ${ }^{(6,7)}$. Diet is one of the main lifestyle-related factors that can regulate the inflammatory process ${ }^{(8)}$. The dietary inflammatory index (DII®) is a tool developed to assess the overall inflammatory potential of an individual's $\operatorname{diet}^{(9,10)}$. It was created by scoring each of the forty-five nutrients and food components that affect CRP, IL-1 $\beta$, IL-4, IL-6, IL-10 and TNF- $\alpha$, using evidence from more than 1900 peer-reviewed journal articles ${ }^{(10)}$.

As the largest developing country in the world, the prevalence of metabolic syndrome is high and rapidly increasing among the elderly population in China ${ }^{(11)}$. Hence, as a result of the huge economic and social burden, metabolic syndrome has become a major challenge for the public healthcare system in China ${ }^{(12)}$. Meanwhile, there are few studies on the relationship between DII and metabolic syndrome in the elderly in China,

Abbreviation: DII, dietary inflammatory index.

* Corresponding author: Yuxia Ma, email mayuxia@hebmu.edu.cn

† These authors contributed equally to this work.

\$ These authors are the co-first authors. 
and there is no consensus on the correlation between them. Thus, this study aimed to evaluate the relationship between DII and the development of the metabolic syndrome and to evaluate its relationship with specific components of metabolic syndrome in the elderly population of northern China.

\section{Materials and methods}

\section{Study population}

This study is a cross-sectional study. Participants in the current study were derived from the baseline of the Community Cohort Study of Nervous System Diseases, an ongoing longitudinal study established by the project in 2018-2019, focusing on potential factors related to the risk of three neurological diseases, including epilepsy in patients $>1$ year old and Alzheimer's disease, Parkinson's disease in people $\geq 55$ years old. The project is undertaken by the Institute of Nutrition and Health of the Chinese Center for Disease Control and Prevention, in cooperation with the Center for Disease Control and Prevention. The project uses a multistage random cluster sampling method to draw samples. The protocol of this study was reviewed and approved by the Institutional Review Board of the National Institute for Nutrition and Health (No. 2017020, 6 November 2017). In addition, written informed consent was obtained for each participant before the survey ${ }^{(13)}$. The present study focuses on elderly people over 55 years of age in the cohort study. In the current analysis, we include data from participants who have complete information about diet and are diagnosed with metabolic syndrome. Finally, a total of 1936 participants were involved in the analysis (Fig. 1).

\section{Metabolic syndrome}

We defined the Adult Treatment Group Recommendation III of the Metabolic Syndrome Cholesterol Education Program under national standards, considering the presence of $\geq 3$ following components: glucose $(\geq 100 \mathrm{mg} / \mathrm{dl})$, TAG $(\geq 150 \mathrm{mg} / \mathrm{dl})$, HDL-cholesterol (male $<40 \mathrm{mg} / \mathrm{dl}$ and $<50 \mathrm{mg} / \mathrm{dl}$ female), BP (systolic blood pressure $\geq 130 \mathrm{mmHg}$ or $\geq 85 \mathrm{mmHg}$ for diastolic blood pressure) and waist circumference (male $\geq 102 \mathrm{~cm}$ or $\geq 88$ cm for female) ${ }^{(14)}$.

\section{Assessment of food consumption}

Dietary consumption is assessed by a validated semi-quantitative FFQ, covering eighty-one food parameters. Participants were asked about the frequency of habitual consumption the number of each item in the past 12 months and choose from five types of frequencies (daily, weekly, monthly, yearly or never) and consumption in the past 12 months. For consumers, their consumption of each food group or item is calculated based on their reported average consumption frequency and quantity.

\section{Diet and dietary inflammatory index}

There are some studies on the development and verification of DII in detail. Research from more than 1900 peer-reviewed publications forms the basis of DII. The 'Inflammatory Effect Score' was created from these peer-reviewed publications for each DII food parameter, based on their impact on inflammatory cytokines. At the same time, standardise DII calculations into a world database with regional representation. This world database includes the dietary consumption of eleven people from all over the world ${ }^{(10)}$. The world database provides standard averages and deviations of all DII food parameters. For each food parameter, create a z-score by subtracting the individual's estimated intake from the standard average. It is then divided by the world standard deviation and converted to a distribution centred at 0 and bounded between -1 and +1 . This value is then multiplied by the inflammatory effect score for each food parameter, and then all food parameters are added together to create an overall DII score. The more positive scores means the more pro-inflammatory diet, the more negative values, the stronger the antiinflammatory effect ${ }^{(10)}$. The DII food ingredients available in the database include carbohydrates, protein, fat, alcohol intake, fibre, cholesterol, saturated and unsaturated (MUFA) and (PUFA) fatty acids, $n-3$ and $n$ - 6 PUFA; niacin; vitamins (A, $\mathrm{B}_{1}, \mathrm{~B}_{2}, \mathrm{~B}_{6}, \mathrm{~B}_{12}$, $\mathrm{C}, \mathrm{D}$ and $\mathrm{E}), \mathrm{Fe}, \mathrm{Mg}, \mathrm{Zn}$, Se, folic acid, $\beta$-carotene and caffeine. DII scores range from negative tail to positive tail, more negative values indicate anti-inflammatory properties and corrected scores indicate pro-inflammatory properties. Energy-adjusted DII (E-DII) food intake per 1000 calories is used to explain the effect of total intake on energy intake $e^{(10,15-17)}$.

\section{Assessment of Covariates}

We adjusted the variables previously identified as potential confounders in the literature. Personal background characteristics include self-reported age (yearly), sex (female or male), education level (illiterate, elementary school, junior high school and above), residence (urban or rural) and employment status (yes or no); health-related variables include tobacco smoking (yes or no), alcohol drinking (yes or no) and physical activity (light, moderate and vigorous).

We used a cut-off value of 28 kilograms per square meter $\left(\mathrm{kg} / \mathrm{m}^{2}\right)$ of China's BMI to determine obesity ${ }^{(18)}$. According to the calculation formula of physical activity level, the weekly accumulated metabolic equivalent (MET) value of the elderly is calculated. Then according to the International Physical Activity Scale evaluation criteria, the level of physical activity of the elderly is divided into light ( $<600 \mathrm{MET} /$ week), moderate (600-3000 MET/week) and vigorous ( $>3000 \mathrm{MET} /$ week ${ }^{(19)}$.

\section{Statistical analysis}

Quantitative data are expressed as the median (interquartile range), and qualitative data are expressed as the number (percentage), respectively, according to DII quartile. For continuous measures, the Wilcoxon-Mann-Whitney test or Fisher's exact compared the change in medians across DII quartiles. $\chi^{2}$ tests were computed to examine the distribution of categorical covariates across quartiles.

Logistic regression and restricted cubic splines regression to simulate the association between the DII quartiles and the metabolic syndrome and calculated OR and $95 \%$ CI to evaluate the relationship between each component of the metabolic 


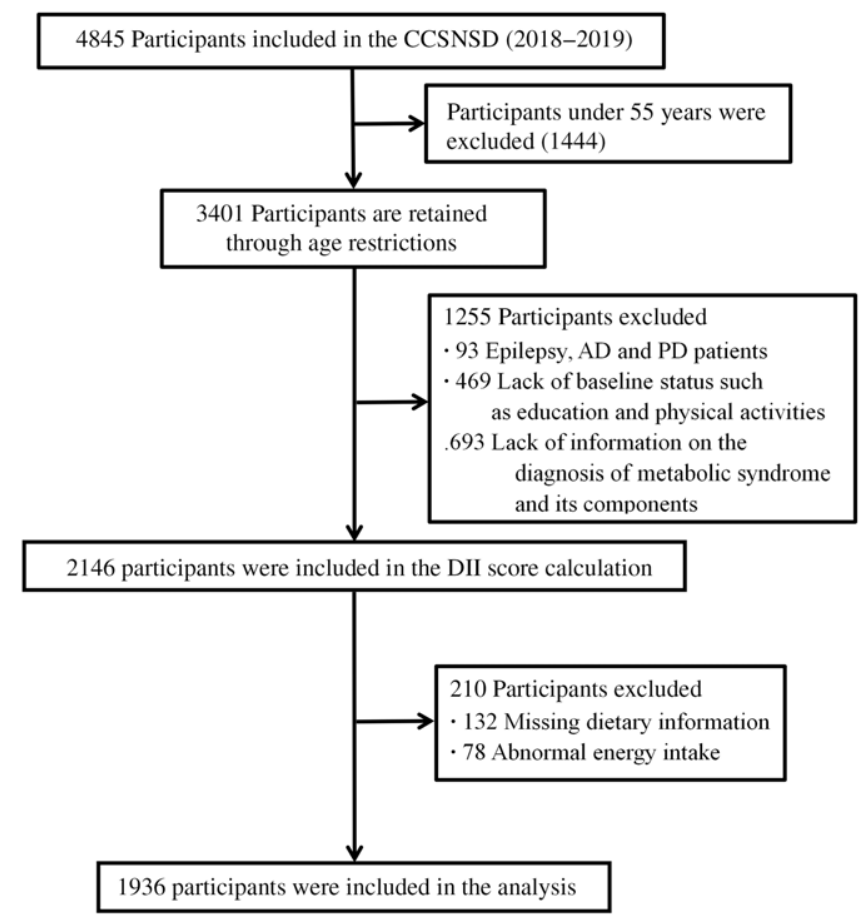

Fig. 1. Selection process of subjects.

syndrome and the DII quartiles. The lowest quartile of the DII score (Q1, reflecting the most anti-inflammatory diet) was used as the reference category. In all cases, we fit a model and adjust the covariates mentioned above. Schoenfeld residuals are used to assess the risk ratio of the model. To optimise the robustness of the statistical test, we conducted a subgroup analysis of BMI $\left(<18 \cdot 5,18 \cdot 5-24 \cdot 0,24-28, \geq 28 \mathrm{~kg} / \mathrm{m}^{2}\right)$. Statistical analyses were all performed with R 3.6.0 software (http://www.R-project.org, The R Foundation). A two-sided $P$-value $<0.05$ was considered to indicate statistical significance.

\section{Results}

Baseline characteristics of the study population are presented by quartiles of the DII score. The DII score ranges from $-5 \cdot 24$ to 5.59. The characteristics of the 1936 participants included in this study are shown in Table 1 . Among the baseline characteristics, only the differences in age and BMI in the different quartiles of DII were statistically significant. $(P<0 \cdot 05)$ Participants with highly pro-inflammatory diets (Q4) had higher levels of TAG $(\mathrm{mg} / \mathrm{dl})$, HDL-cholesterol $(\mathrm{mg} / \mathrm{dl})$ and systolic $\mathrm{BP}(\mathrm{mmHg})$.

The relationship between the metabolic syndrome as a whole and its components and DII quartile is presented in Table 2. In the fully adjusted model, the risk of metabolic syndrome increased by 1.28 -fold in people with a pro-inflammatory diet $\left(\mathrm{OR}_{\mathrm{Q} 4} v . \quad \mathrm{Q} 1=1.28 ; 95 \%\right.$ CI: $1.08,1.56 ; P_{\text {linear- }}$ trend $=0.03)$. When we divide the metabolic syndrome by its components, high pro-inflammatory diet and hyperglycaemia $\left(\mathrm{OR}_{\mathrm{Q} 4} v \cdot \mathrm{Q} 1=1 \cdot 23 ; 95 \% \mathrm{CI}: 1 \cdot 05,1 \cdot 49 ; P_{\text {linear-trend }}=0 \cdot 04\right), \mathrm{TAG}$ $\left(\mathrm{OR}_{\mathrm{Q} 4} v \cdot \mathrm{Q}_{1}=1.39 ; 95 \% \mathrm{CI}: 1.12,1.65 ; P_{\text {linear-trend }}=0.02\right)$, hypertension $\left(\mathrm{OR}_{\mathrm{Q} 4 v \cdot \mathrm{Q} 1}=1 \cdot 28 ; 95 \% \mathrm{CI}: 1 \cdot 09,1 \cdot 51 ; P_{\text {linear-trend }}\right.$ $=0.03)$ and abdominal obesity $\left(\mathrm{OR}_{\mathrm{Q} 4 v . \mathrm{Q} 1}=1.59 ; 95 \% \mathrm{CI}: 1 \cdot 18\right.$, $\left.2 \cdot 06 ; P_{\text {linear-trend }}=0.01\right)$. We failed to observe a significant association between a high pro-inflammatory diet and HDLcholesterol. However, these associations are moving in the expected direction. There is a potential increase in the risk of HDL-cholesterol observed in the pro-inflammatory diet quartile, but the difference is not significant. Restricted cubic splines regression also shows that DII is positively and nonlinearly correlated with metabolic syndrome, hyperglycaemia, high TAG, hypertension and abdominal obesity $\left(P_{\text {nonlinear-trend }}<0.05\right)$ (online Supplementary Fig. 1 ).

Table 3 shows the results of the stratified analysis grouped by BMI. In different stratified groups, compared with the least pro-inflammatory diet group (Q1), the DII pro-inflammatory diet group has a different degree of risk in metabolic syndrome and its different components. In the group of overweight, highly pro-inflammatory diets were associated with hyperglycaemia $\left(\mathrm{OR}_{\mathrm{Q} 4} v \cdot \mathrm{Q}_{1}=1 \cdot 18 ; 95 \% \mathrm{CI}: 1.05,1.62 ; P_{\text {linear-trend }}\right.$ =0.02), hypertension $\left(\mathrm{OR}_{\mathrm{O} 4}=1.35 ; 95 \% \mathrm{CI}: 1.13,1.96\right.$; $\left.P_{\text {linear-trend }}=0 \cdot 01\right)$ and abdominal obesity $\left(\mathrm{OR}_{\mathrm{Q} 4} v \cdot \mathrm{Q}_{1}=2 \cdot 28\right.$; $95 \%$ CI: $\left.1 \cdot 36,3 \cdot 12 ; P_{\text {linear-trend }}=0 \cdot 008\right)$. In the obese category, the risk of metabolic syndrome of the most pro-inflammatory diet is 2.18 times that of the least pro-inflammatory diet group $\left(\mathrm{OR}_{\mathrm{Q} 4} v \cdot \mathrm{Q}_{1}=2.15 ; 95 \% \mathrm{CI}: 1.08,3.28 ; P_{\text {linear-trend }}=0.02\right)$. Immensely pro-inflammatory diets are correlated with hyperglycaemia $\left(\mathrm{OR}_{\mathrm{Q} 4} v \cdot \mathrm{Q} 1=1.42 ; 95 \% \mathrm{CI}: 1.15,1.92 ; P_{\text {linear-trend }}\right.$ $=0 \cdot 006)$, TAG $\left(\mathrm{OR}_{\mathrm{O} \text { i }}=1 \cdot 56 ; 95 \% \mathrm{CI}: 1 \cdot 06,2 \cdot 32 ; P_{\text {linear-trend }}\right.$ $=0.03)$, hypertension $\left(\mathrm{OR}_{\mathrm{Q} 4} v \cdot \mathrm{Q}_{1}=1 \cdot 36 ; 95 \% \mathrm{CI}: 1 \cdot 12,2 \cdot 32\right.$; $\left.P_{\text {linear-trend }}=0 \cdot 009\right)$ and abdominal obesity $\left(\mathrm{OR}_{\mathrm{Q} 4} v \cdot \mathrm{Q} 1=2 \cdot 01\right.$; $95 \%$ CI: $\left.1 \cdot 20,3 \cdot 06 ; P_{\text {linear-trend }}=0 \cdot 006\right)$. At the same time, the results grouped by sex showed that there is no significant 
Table 1. Baseline characteristics and components of metabolic syndrome of the community cohort study of nervous system diseases (CCSNSD) project population across quartiles of the DII score (Frequency and percentages; median values and interquartile range)

\begin{tabular}{|c|c|c|c|c|c|c|c|c|c|}
\hline \multirow[b]{2}{*}{ Characteristic } & \multicolumn{2}{|c|}{ Quartile 1 ( $n$ 483) } & \multicolumn{2}{|c|}{ Quartile 2 ( $n$ 484) } & \multicolumn{2}{|c|}{ Quartile 3 ( $n$ 485) } & \multicolumn{2}{|c|}{ Quartile 4 (n 484) } & \multirow[b]{2}{*}{$P$-value } \\
\hline & Frequency & $\%$ & Frequency & $\%$ & Frequency & $\%$ & Frequency & $\%$ & \\
\hline Age (years) & & & & & & & & & $<0.001$ \\
\hline $\begin{array}{l}\text { Median } \\
\text { IQR }\end{array}$ & \multicolumn{2}{|c|}{$\begin{array}{c}68 \\
64.0-73.0\end{array}$} & \multicolumn{2}{|c|}{$\begin{array}{c}65 \\
60 \cdot 0-70 \cdot 0\end{array}$} & \multicolumn{2}{|c|}{$\begin{array}{c}63 \\
59.0-68 \cdot 0\end{array}$} & \multicolumn{2}{|c|}{$\begin{array}{c}64 \\
60 \cdot 0-69 \cdot 0\end{array}$} & \\
\hline Sex & & & & & & & & & 0.938 \\
\hline Male & 189 & 39.1 & 180 & $37 \cdot 2$ & 183 & $37 \cdot 7$ & 184 & 38.0 & \\
\hline Female & 294 & 60.9 & 304 & $62 \cdot 8$ & 302 & $62 \cdot 3$ & 300 & $62 \cdot 0$ & \\
\hline \multicolumn{10}{|l|}{ BMI $\left(\mathrm{kg} / \mathrm{m}^{2}\right)$} \\
\hline $\mathrm{BMI}<18.50$ (underweight) & 9 & 1.9 & 22 & 4.5 & 13 & $2 \cdot 7$ & 12 & 2.5 & 0.010 \\
\hline $18.50 \leq \mathrm{BMI}<24.00$ (normal weight) & 165 & 34.2 & 204 & $42 \cdot 1$ & 202 & 41.6 & 174 & $36 \cdot 0$ & \\
\hline $24.00 \leq \mathrm{BMI}<28.00$ (overweight) & 203 & $42 \cdot 0$ & 185 & 38.2 & 180 & $37 \cdot 1$ & 197 & $40 \cdot 7$ & \\
\hline $\mathrm{BMI} \geq 28.00$ (obese) & 106 & 21.9 & 73 & $15 \cdot 1$ & 90 & $18 \cdot 6$ & 101 & 20.9 & \\
\hline \multicolumn{9}{|l|}{ Residence } & 0.520 \\
\hline Urban & 126 & $26 \cdot 1$ & 140 & 28.9 & 141 & $29 \cdot 1$ & 125 & $25 \cdot 8$ & \\
\hline Rural & 357 & 73.9 & 344 & $71 \cdot 1$ & 344 & $70 \cdot 9$ & 359 & 74.2 & \\
\hline \multicolumn{9}{|l|}{ Employment } & 0.174 \\
\hline No & 427 & 88.4 & 409 & 84.5 & 406 & $83 \cdot 7$ & 415 & $85 \cdot 7$ & \\
\hline \multirow{2}{*}{\multicolumn{9}{|c|}{ Education }} & \\
\hline & & & & & & & & & 0.089 \\
\hline Illiteracy & 122 & $25 \cdot 3$ & 133 & 27.5 & 108 & $22 \cdot 3$ & 118 & 24.4 & \\
\hline Primary school & 174 & 36.0 & 158 & 32.6 & 150 & $30.9 \%$ & 147 & 30.4 & \\
\hline \multirow{2}{*}{\multicolumn{9}{|c|}{ Tobacco smoking }} & \\
\hline & & & & & & & & & 0.485 \\
\hline No & 399 & $82 \cdot 6$ & 407 & $84 \cdot 1$ & 418 & $86 \cdot 2$ & 405 & $83 \cdot 7$ & \\
\hline Yes & 84 & $17 \cdot 4$ & 77 & $15 \cdot 9$ & 67 & $13 \cdot 8$ & 79 & $16 \cdot 3$ & \\
\hline \multicolumn{9}{|l|}{ Physical activities } & 0.296 \\
\hline Light (<600 MET/week) & 139 & 28.8 & 137 & $28 \cdot 3$ & 135 & $27 \cdot 8$ & 135 & 27.9 & \\
\hline Moderate (600-3000 MET/week) & 240 & 49.7 & 236 & 48.8 & 235 & $48.5 \%$ & 233 & $48 \cdot 1$ & \\
\hline \multirow{2}{*}{ Vigorous (>3000 MET/week) } & 104 & 21.5 & 111 & $22 \cdot 9$ & 115 & $23 \cdot 7$ & 116 & 24.0 & \\
\hline & Median & IQR & Median & IQR & Median & IQR & Median & IQR & \\
\hline Glucose (mg/dl) & 5.60 & $5 \cdot 14-6 \cdot 40$ & 5.57 & $5 \cdot 11-6 \cdot 28$ & 5.49 & $5.05-6.28$ & $5 \cdot 60$ & $5.07-6 \cdot 26$ & 0.268 \\
\hline TAG (mg/dl) & 1.48 & $1.06-2.08$ & 1.35 & $0.95-1.90$ & 1.35 & $0.99-1.98$ & 1.36 & $1.02-1.98$ & 0.012 \\
\hline HDL-cholesterol (mg/dl) & 1.24 & $1.04-1.49$ & 1.33 & $1.08-1.59$ & 1.30 & $1.10-1.56$ & 1.26 & $1.06-1.51$ & 0.012 \\
\hline Systolic BP (mmHg) & 135 & $125 \cdot 0-147 \cdot 0$ & 132 & $121 \cdot 0-144 \cdot 0$ & 132.5 & $122 \cdot 0-143 \cdot 0$ & 134 & $122 \cdot 0-145 \cdot 0$ & 0.007 \\
\hline Diastolic BP $(\mathrm{mmHg})$ & 82 & $75 \cdot 0-89 \cdot 0$ & 81 & $75 \cdot 0-90 \cdot 0$ & 82 & $75 \cdot 0-89 \cdot 0$ & 81.8 & $75 \cdot 0-89 \cdot 0$ & 0.977 \\
\hline Waist circumference $(\mathrm{cm})$ & 90 & $84 \cdot 0-97 \cdot 1$ & 90 & $82 \cdot 0-97 \cdot 0$ & 89 & $83 \cdot 2-96 \cdot 0$ & 90 & $84 \cdot 0-96 \cdot 2$ & 0.489 \\
\hline
\end{tabular}

DII, dietary inflammatory index; MET, metabolic equivalent.
Quartile 1: -5.24-0.81; Quartile 2: 0.81-1.81; Quartile 3: 1.81-2.54; Quartile 4: 2.54-5.59. 
gender difference in the correlation between DII and metabolic syndrome (online Supplementary Table 1).

\section{Discussion}

This study aims to assess the association between DII scores and the incidence of metabolic syndrome in samples of healthy elderly people from northern China. Compared with participants on a highly anti-inflammatory diet, people on a highly inflammatory diet had a 1.28 times the risk of developing metabolic syndrome. In addition, we have observed that consumers on a highly inflammatory diet are at higher risk of hypertriglyceridaemia, hypertension, hyperglycaemia and abdominal obesity. At the same time, the results of BMI subgroup analysis showed that with the increase of DII, obese people are at increased risk of metabolic syndrome, hyperglycaemia, high TAG, hypertension and abdominal obesity. Also in overweight people, the increase in DII is accompanied by an increased risk of hyperglycaemia and abdominal obesity.

The possible reason for the results of the study is that we found that a highly pro-inflammatory diet is characterised by an unhealthy diet. Participants on a high-inflammatory diet consumed more SFA, which increased TAG reserves in adipose tissue by activating the inflammatory response ${ }^{(20)}$. They also consume fewer antioxidants, which can change the redox balance, cause endothelial damage and further increase the inflammatory response. Red meat is also often eaten; this is related to an increase in soluble adhesion molecules ${ }^{(21,22)}$. The consumption of soft drinks (fructose) is related to the activation of different mechanisms that promote inflammation. Fructose promotes the activation of oxidative stress and NF- $\mathrm{KB}$, thereby inducing stress response through liver and lipid metabolism disorders ${ }^{(23)}$.

The relationship between metabolic syndrome and dietary inflammation index may be related to dietary patterns. Eating patterns are one of the best ways to assess the relationship between diet and disease. In different studies, the positive effects of healthy eating patterns in preventing cancer, diabetes and obesity have been proven. Recently, it has been shown that the anti-inflammatory DII score is positively correlated with some healthy eating patterns, such as DASH (Eat Method to Prevent High Blood Pressure), Alternative Healthy Eating Index and Healthy Eating Index-2010 (24-26).

We found an association between DII and the three components of metabolic syndrome: hypertriglyceridaemia, hypertension, abdominal obesity and blood sugar levels; we did not observe an association with HDL-cholesterol. The specific components of the metabolic syndrome and their relationship with DII were analysed only in cross-sectional studies. In the USA, a cross-sectional study of the police population observed a higher prevalence of hyperglycaemia in participants with proinflammatory DII ${ }^{(27)}$. This is consistent with our research results. At the same time, a study was conducted in eight cities in China to observe the association between DII and the risk of hypertension, and the strength of the association was similar to our research results ${ }^{(28)}$. In addition, a study conducted among Polish adults found an association between DII and risk of abdominal obesity in men $\left(\mathrm{OR}_{\mathrm{Q} 4} v \cdot \mathrm{Q}_{1}=1 \cdot 65 ; 95 \% \mathrm{CI}\right.$ : $1 \cdot 01$, 
Table 3. Subgroup analysis of association between dietary inflammatory index and sex hormones among different BMI groups in CCSNSD 2017-2018 (Odd ratio and $95 \%$ confidence intervals)

\begin{tabular}{|c|c|c|c|c|c|c|c|c|c|c|c|c|}
\hline \multirow[b]{3}{*}{ Dietary Inflammatory Index Group } & \multicolumn{12}{|c|}{ Dyslipidaemia } \\
\hline & \multicolumn{2}{|c|}{$\begin{array}{l}\text { Metabolic syndrome } \\
\qquad(n \text { 828) }\end{array}$} & \multicolumn{2}{|c|}{$\begin{array}{l}\text { Hyperglycaemia } \\
(n 975)\end{array}$} & \multicolumn{2}{|c|}{ TAG $(n 671)$} & \multicolumn{2}{|c|}{$\begin{array}{l}\text { HDL-cholesterol } \\
\quad(n 773)\end{array}$} & \multicolumn{2}{|c|}{ Hypertension $(n$ 1270) } & \multicolumn{2}{|c|}{$\begin{array}{c}\text { Abdominal obesity } \\
(n 786)\end{array}$} \\
\hline & OR & $95 \% \mathrm{Cl}$ & OR & $95 \% \mathrm{Cl}$ & OR & $95 \% \mathrm{Cl}$ & OR & $95 \% \mathrm{Cl}$ & OR & $95 \% \mathrm{Cl}$ & OR & $95 \% \mathrm{Cl}$ \\
\hline \multicolumn{13}{|l|}{$\mathrm{BMI}<18.50$ (underweight) } \\
\hline Quartile $1(n 9)$ & 1.00 (Ref) & & 1.00 (Ref) & & 1.00 (Ref) & & 1.00 (Ref) & & 1.00 (Ref) & & 1.00 (Ref) & \\
\hline Quartile 2 ( $n$ 22) & 1.12 & $0.39,1.89$ & 0.59 & $0.25,1.13$ & 1.05 & $0.67,1.16$ & 0.87 & $0.35,1.36$ & 0.92 & $0.57,1.32$ & 1.08 & $0.39,2.87$ \\
\hline Quartile $3(n 13)$ & 1.39 & $0.58,2.03$ & 1.09 & $0.35,1.96$ & $1 \cdot 12$ & $0.86,1.39$ & 1.15 & $0.86,1.67$ & 1.25 & $0.81,2.32$ & 1.35 & $0.60,3.12$ \\
\hline Quartile 4 ( $n$ 12) & 1.62 & $0.67,2.86$ & 0.63 & $0.32,3.02$ & $1 \cdot 19$ & $0.82,1.56$ & 1.08 & $0.62,1.58$ & 1.58 & $0.93,2.96$ & 1.46 & $0.82,3.69$ \\
\hline$P$-trend & 0.52 & & 0.49 & & 0.23 & & 0.61 & & 0.42 & & 0.16 & \\
\hline \multicolumn{13}{|l|}{$18.50 \leq \mathrm{BMI}<24.00$ (normal weight) } \\
\hline Quartile $1(n$ 165) & 1.00 (Ref) & & 1.00 (Ref) & & 1.00 (Ref) & & 1.00 (Ref) & & 1.00 (Ref) & & 1.00 (Ref) & \\
\hline Quartile 2 (n 204) & 1.05 & $0.62,1.63$ & 1.03 & $0.67,1.62$ & 0.86 & $0.49,1.31$ & 0.69 & $0.46,1.21$ & 1.06 & $0.69,1.56$ & 1.23 & $0.72,2.08$ \\
\hline Quartile 3 (n 202) & 1.09 & $0.56,1.56$ & 1.25 & $0.79,1.93$ & 1.13 & $0.49,1.37$ & 1.05 & $0.68,1.63$ & 0.72 & $0.43,1.19$ & 1.45 & $0.86,2.39$ \\
\hline Quartile 4 ( $n$ 174) & $1 \cdot 16$ & $0.72,1.85$ & 1.29 & $0.85,1.98$ & 1.28 & $0.62,1.59$ & 1.26 & $0.78,2.02$ & $1 \cdot 12$ & $0.67,1.75$ & 1.08 & $0.60,1.76$ \\
\hline \multirow{2}{*}{\multicolumn{13}{|c|}{$24.00 \leq \mathrm{BMI}<28.00$ (overweight) }} \\
\hline & & & & & & & & & & & & \\
\hline Quartile 1 (n 203) & 1.00 (Ref) & & 1.00 (Ref) & & 1.00 (Ref) & & 1.00 (Ref) & & 1.00 (Ref) & & 1.00 (Ref) & \\
\hline Quartile 2 ( $n$ 185) & 1.09 & $0.73,1.68$ & 1.03 & $0.53,1.25$ & 1.15 & $0.57,1.52$ & 0.86 & $0.58,1.26$ & 0.82 & $0.53,1.26$ & 1.78 & $1 \cdot 12,2 \cdot 90$ \\
\hline Quartile 3 ( $n$ 180) & $1 \cdot 15$ & $0.59,2.23$ & $1 \cdot 12$ & $0.64,1.36$ & 1.26 & $0.57,1.90$ & 1.01 & $0.62,1.34$ & $1 \cdot 12$ & $1.03,1.26$ & 2.02 & $1.28,3.19$ \\
\hline Quartile 4 ( $n$ 197) & 1.23 & $0.67,2.41$ & 1.18 & $1.05,1.62$ & 1.67 & $0.79,2 \cdot 16$ & 1.12 & $0.73,1.49$ & 1.35 & $1.13,1.96$ & $2 \cdot 28$ & $1.36,3.62$ \\
\hline Ptrend & 0.57 & & 0.02 & & 0.19 & & 0.25 & & 0.01 & & 0.008 & \\
\hline \multicolumn{13}{|l|}{$\mathrm{BMI} \geq 28.00$ (obese) } \\
\hline Quartile 1 ( $n$ 106) & 1.00 (Ref) & & 1.00 (Ref) & & 1.00 (Ref) & & 1.00 (Ref) & & 1.00 (Ref) & & 1.00 (Ref) & \\
\hline Quartile 2 ( $n 73)$ & 1.08 & $0.96,2.05$ & 1.06 & $0.76,1.52$ & 1.15 & $0.65,1.96$ & 1.03 & $0.52,1.86$ & 0.76 & $0.39,1.47$ & 1.26 & $1.05,1.89$ \\
\hline Quartile $3(n 90)$ & 1.63 & $1 \cdot 06,2 \cdot 18$ & 1.23 & $1.08,1.68$ & 1.29 & $0.75,2.02$ & $1 \cdot 19$ & $0.48,1.65$ & 1.08 & $0.62,2.06$ & 1.52 & $1 \cdot 16,2 \cdot 35$ \\
\hline Quartile 4 (n 101) & $2 \cdot 15$ & $1.08,3.28$ & 1.42 & $1.15,1.92$ & 1.56 & $1.06,2.32$ & 1.35 & $0.97,2.56$ & 1.36 & $1 \cdot 12,2 \cdot 32$ & 2.01 & $1.20,3.06$ \\
\hline$P_{\text {trend }}$ & 0.02 & & 0.006 & & 0.03 & & 0.26 & & 0.009 & & 0.006 & \\
\hline
\end{tabular}


$2 \cdot 69)^{(28)}$. We observed a similar correlation. Participants with the highest DII levels had a 1.59-fold increased risk of abdominal obesity $\left(\mathrm{OR}_{\mathrm{Q} 4 v \cdot \mathrm{Q} 1}=1 \cdot 59 ; 95 \% \mathrm{CI}: 1 \cdot 18,2 \cdot 06 ; P_{\text {linear-trend }}=0 \cdot 01\right)$. Our results did not find an association between DII and HDL-cholesterol. This requires further research to assess the association of DII with specific components of the metabolic syndrome, to assess the robustness of our research and to better understand the underlying mechanisms of inflammatory diets affecting health.

As far as we know, the present study is the first to explore the association between DII and metabolic syndrome in the elderly over 55 years in China. All of the participants recruited into the cohort are from the same province, their income, education and serological indicators are not representative. Thus, the dietary intake observed in the cohort is not necessarily similar to the national elderly. Nonetheless, our research still captured enough variation in the diet to observe a link between quartile DII and metabolic syndrome. There are several limitations in our study. First, the dietary consumption level is estimated based on the FFQ covering the past 12 months, which may have a certain recall bias. Another potential limitation is that among the forty-five food parameters, only twenty-two food parameters can be used in the DII calculation in this article, and the estimation of the potential of dietary inflammation may be biased. Although we carefully adjusted some covariates in the data analysis, there may still be residual confusion ${ }^{(10,29)}$. In addition, the cross-sectional nature of our research does not allow us to draw any causal conclusions.

\section{Conclusion}

Our results showed that higher inflammatory diet is related to metabolic syndrome, hypertension, hyperglycaemia, abdominal obesity and hypertriglyceridaemia. The trend was also evident in overweight and obese people. Further research is needed to confirm the role of inflammation and diet in the development of metabolic syndrome; however, it is desirable to reduce the dietary components associated with inflammation.

\section{Acknowledgements}

The present study uses data from the CCSNSD. We thank all of the participants and staff involved in the surveys.

Community Cohort Study on Specialized Nervous System Diseases (No. 2017YFC0907701)

Y. M. and R. L. had full access to all of the data in the study and take responsibility for the integrity of the data and the accuracy of the data analysis. Concept and design: Y. M. and R. L. Acquisition, analysis or interpretation of data: All authors. Drafting of the manuscript: Y. M., R. L. and W. Z. Critical revision of the manuscript for important intellectual content: All authors. Statistical analysis: R. L., W. Z., Z. Z. and M. Z. Obtained funding: Y. M. and W. B. Administrative, technical or material support: R. L., W. Z., Z. Z. and X. H. Supervision: Y. M.

There are no conflicts of interest.

\section{Supplementary material}

For supplementary material/s referred to in this article, please visit https://doi.org/10.1017/S0007114521004207

\section{References}

1. Taghipour Yasamin D, Hajialyani M, Naseri R, et al. (2019) Nanoformulations of natural products for management of metabolic syndrome. Int J Nanomed 14, 5303-5321.

2. Prasun P (2020) Mitochondrial dysfunction in metabolic syndrome. Biochim Biophys Acta Mol Basis Dis 1866, 165838.

3. Ortiz-Rodríguez MA, Yáñez-Velasco L, Carnevale A, et al. (2017) Prevalence of metabolic syndrome among elderly Mexicans. Arch Gerontol Geriatr 73, 288-293.

4. Dziegielewska-Gesiak S (2021) Metabolic syndrome in an aging society - role of oxidant-antioxidant imbalance and inflammation markers in disentangling atherosclerosis. Clin Interv Aging 16, 1057-1070.

5. Zhu Y, Wan N, Shan X, et al. (2021) Celastrol targets adenylyl cyclase-associated protein 1 to reduce macrophages-mediated inflammation and ameliorates high fat diet-induced metabolic syndrome in mice. Acta Pharm Sin B 11, 1200-1212.

6. León-Pedroza JI, González-Tapia LA, del Olmo-Gil E, et al. (2015) Low-grade systemic inflammation and the development of metabolic diseases: from the molecular evidence to the clinical practice. Cir Cir 83, 543-551.

7. Minihane Anne M, Vinoy S, Russell Wendy R, et al. (2015) Lowgrade inflammation, diet composition and health: current research evidence and its translation. Br J Nutr 114, 999-1012.

8. Laouali N, Mancini Francesca R, Hajji-Louati M, et al. (2019) Dietary inflammatory index and type 2 diabetes risk in a prospective cohort of 70991 women followed for 20 years: the mediating role of BMI. Diabetologia 62, 2222-2232.

9. Cavicchia Philip P, Steck Susan E, Hurley Thomas G, et al. (2009) A new dietary inflammatory index predicts interval changes in serum high-sensitivity C-reactive protein. $J$ Nutr 139, 2365-2372.

10. Shivappa N, Steck Susan E, Hurley Thomas G, et al. (2014) Designing and developing a literature-derived, populationbased dietary inflammatory index. Public Health Nutr 17, 1689-1696.

11. Nie G, Hou S, Zhang M, et al. (2021) High TG/HDL ratio suggests a higher risk of metabolic syndrome among an elderly Chinese population: a cross-sectional study. BMJ Open 11, e041519.

12. Li R, Li Q, Cui M, et al. (2018) Clinical surrogate markers for predicting metabolic syndrome in middle-aged and elderly Chinese. J Diabetes Investig 9, 411-418.

13. Huang F, Wang H, Wang Z, et al. (2021) Is geriatric depression scale a valid instrument to screen depression in Chinese community-dwelling elderly? BMC Geriatr 21, 310.

14. Huang Paul L (2009) A comprehensive definition for metabolic syndrome. Dis Model Mech 2, 231-237.

15. Shivappa N, Steck Susan E, Hurley Thomas G, et al. (2014) A population-based dietary inflammatory index predicts levels of C-reactive protein in the seasonal variation of blood cholesterol study (SEASONS). Public Health Nutr 17, 1825-1833.

16. Tabung FK, Smith-Warner SA, Chavarro JE, et al. (2016) Development and validation of an empirical dietary inflammatory index. J Nutr 146, 1560-1570.

17. Mazidi M, Shivappa N, Wirth MD, et al. (2017) The association between dietary inflammatory properties and bone mineral 
density and risk of fracture in US adults. Eur J Clin Nutr $\mathbf{7 1}$, 1273-1277.

18. National Health and Family Planning Commission of the People's Republic of China (2013) Criteria of Weight for Adults, WS/T 428-2013. Beijing: Standards Press of China.

19. Ainsworth BE, Haskell WL, Whitt MC, et al. (2000) Compendium of physical activities: an update of activity codes and MET intensities. Med Sci Sport Exerc 32, S498-S504.

20. Santos S, Oliveira A \& Lopes C (2013) Systematic review of saturated fatty acids on inflammation and circulating levels of adipokines. Nutr Res 33, 687-695.

21. Kontogianni MD, Zampelas A \& Tsigos C (2006) Nutrition and inflammatory load. Ann NY Acad Sci 1083, 214-238.

22. Aeberli I, Gerber Philipp A, Hochuli M, et al. (2011) Low to moderate sugar-sweetened beverage consumption impairs glucose and lipid metabolism and promotes inflammation in healthy young men: a randomized controlled trial. Am J Clin Nutr 94, 479-485.

23. Roglans N, Vilà L, Farré M, et al. (2007) Impairment of hepatic Stat-3 activation and reduction of PPAR $\alpha$ activity in fructose-fed rats. Hepatology 45, 778-788.

24. Juraschek Stephen P, Kovell Lara C, Appel Lawrence J, et al. (2021) Effects of diet and sodium reduction on cardiac injury, strain, and inflammation: the DASH-sodium trial. J Am Coll Cardiol 77, 2625-2634.
25. Asadi Z, Ghaffarian Zirak R, Yaghooti Khorasani M, et al. (2020) Dietary inflammatory index is associated with healthy eating index, alternative healthy eating index, and dietary patterns among Iranian adults. J Clin Lab Anal 34, e23523.

26. Johnston Carol S, Bliss C, Knurick Jessica R, et al. (2018) Rapid eating assessment for participants shortened version. Scores are associated with Healthy Eating Index-2010 scores and other indices of diet quality in healthy adult omnivores and vegetarians. Nutr J 17, 89 .

27. Wirth Michael D, Burch J, Shivappa N, et al. (2014) Association of a dietary inflammatory index with inflammatory indices and metabolic syndrome among police officers. J Occup Environ Med 56, 986-989.

28. Ren Z, Zhao A, Wang Y, et al. (2018) Association between dietary inflammatory index, c-reactive protein and metabolic syndrome: a cross-sectional study. Nutrients 10, 831.

29. Shivappa N, Wirth Michael D, Murphy EA, et al. (2019) Association between the Dietary Inflammatory Index (DII) and urinary enterolignans and C-reactive protein from the National Health and Nutrition Examination Survey-20032008. Eur J Nutr 58, 797-805.

30. Lopez-Garcia E, Schulze MB, Fung TT, et al. (2004) Major dietary patterns are related to plasma concentrations of markers of inflammation and endothelial dysfunction. Am J Clin Nutr 80, 1029-1035. 